\title{
CALCULATION OF PAVEMENT PERMANENT DEFORMATION USING PERZYNA'S ELASTO-VISCOPLASTIC MODEL
}

\author{
Nguyen Huynh Tan Tai ${ }^{1,2, *}$

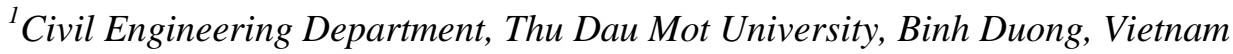 \\ ${ }^{2}$ Research-Development and Testing Division, BMT Investment Construction Joint Stock \\ Company, Ho Chi Minh City, Vietnam \\ "Email: tainht@tdmu.edu.vn,tainht@bmt-rnd.vn
}

Received: 28 November 2014; Accepted for publication: 24 November 2015

\begin{abstract}
In this work, a method for calculation of pavement permanent deformation due to traffic loading is presented. The mechanics behavior of asphalt concrete layer is considered as Perzyna's elasto-viscoplastic material. The pavement permanent deformation is incrementally calculated using nonlinear finite element method. Model parameters are determined using Hamburg Wheel Tracking Test result.
\end{abstract}

Keyworks: pavement permanent deformation, rut depth prediction, elasto-viscoplastic model, finite deformation.

\section{INTRODUCTION}

Pavement permanent deformation (or rutting) is a common distress of pavement structure in Vietnam. The cause of this kind of distress is due to the fact that the asphalt concrete pavement does not completely recover its deformation under the action of repeated vehicle loading. With tropical climate in Vietnam, the temperature in asphalt concrete surface layer can reach more than $70{ }^{\circ} \mathrm{C}$ at hottest time of the day. This temperature exceeds softening point of most bitumen used and therefore facilitates rutting formation.

Asphalt concrete is a material with viscous and plastic properties. When loading is applied and released, there exists an irreversible part of deformation called plastic deformation. After a certain number of load passes, plastic deformation is cumulated enough to create ruts on pavement surface, which cause difficulty with vehicles traveling on it. Prediction methods are necessary for pavement engineers to analyze the long-term behavior of pavement and select the suitable material based on analysis results. There are two groups of prediction methods, namely analytical and numerical methods.

In the analytical methods, elasticity theory or finite element method is used for analyzing stress, strain distribution in pavement structure and analytical models are proposed to predict rut depth of pavement in function of stress or strain. Typical models are those developed by Shell in 1978 and Asphalt Institute in 1982. It is assumed that rut depth is a function of normal stress in 
Shell method, and therefore uniaxial creep test is used for evaluating stiffness of asphalt concrete. Base on creep test results, rut depth of the pavement structure is calculated as the summation of that caused by every sublayer. Rut depth is considered, however, as a function of vertical strain at top of base layer in Asphalt Institute method, which is widely inspired in the design standards, namely AASHTO [1], IRC: 37-2012 [2]. Model parameters used in these design codes are determined and calibrated by means of data measured on Test Track facilities, which depend strongly on traffic and weather conditions of host country. The methods mentioned above do not take into account the hardening effect of material and interaction between layers in the pavement structure. In VESYS method [3-4], irreversible deformation of a load pass is assumed proportional to elastic deformation and has its value decreasing with number of load passes as a result of hardening effect disregarding loading time of every load pass.

Second methods relate to numerical methods modeling the behavior of pavement structure under repeated vehicle loading. Asphalt concrete is assumed viscoplasticity in Refs. [5 - 7] or elasto-viscoplasticity in Refs. [8 - 10] or, more complicated, viscoelasto-viscoplasticity in [11 13]. Due to rearrangement of aggregates, permanent deformation rate decreases with time, and therefore hardening laws are added to material constitutive laws. In Ref. [9], the authors proposed that hardening modulus decreasing with number of load passes, whereas cumulative equivalent plastic strain is used in Refs. $[8,10]$ as a quantity to characterize the deformation state of material instead of either number of load passes or total loading time. None of models mentioned above takes into account large deformation effects. When rutting occurs, pavement structure undergoes rather large displacement; therefore, geometric nonlinearity must be considered in the formulation.

The objectives of this study is to modify Perzyna's elasto-viscoplastic model [14] for asphalt concrete material in large deformation conditions. The results of this work is used for stress, strain analysis of pavement structure and rut depth prediction. Specific objectives are those below

- modification of Perzyna's elasto-viscoplastic model using Drucker-Prager criteria for asphalt concrete material in large deformation conditions; implementation of proposed constitutive law in finite element method

- application of Hamburg Wheel Tracking test results to predict flexible pavement permanent deformation

- validation of method proposed on the basis of monitoring data of specific projects

\section{PERZYNA'S ELASTO-VISOPLASTIC MODEL}

Let $\stackrel{\bar{\Sigma}}{ }$ denote second Piola-Kirchhoff stress tensor which describes stress state of a rigid body in equilibrium under exterior loads and effects. Unless otherwise stated, Einstein summation convention is used throughout and the sign " " " denotes a tensor of second order. The local equilibrium equation of a solid body at any point is written by Eq. (1)

$$
\overrightarrow{D i v} \bar{\Sigma}+\rho \vec{f}=0
$$

where $\rho$ is density of body, $\vec{f}$ is prescribed body force of unit mass and $\overrightarrow{D i v}$ operator is defined as $(\overrightarrow{D i v} \overline{\bar{\Sigma}})_{i}=\frac{\partial \Sigma i j}{\partial X_{j}}$. Let $\overline{\bar{E}}$ denote Green Lagrange strain tensor. Asphalt concrete 
material deforms when loads are applied on it and recovers a part of its deformation when loads are released. One can therefore decompose strain tensor into elastic and viscoplastic strain tensors as follow

$$
\overline{\bar{E}}=\overline{\bar{E}}^{e}+\overline{\bar{E}}^{v p}
$$

Stress - elastic strain relationship obeys Saint-Venant Kirchhoff's law

$$
\overline{\bar{\Sigma}}=2 \mu \overline{\bar{E}}^{e}+\lambda t r \overline{\bar{E}}^{\mathrm{e}} \cdot \overline{\bar{I}}
$$

where $\overline{\bar{I}}$ is second order tensor of unity; $\mu$ is shear modulus and $\lambda$ is Lamé constant.

Let decompose stress tensor into summation of deviatoric part $\overline{\bar{S}}$ and spherical part $p . \overline{\bar{I}}$

\section{Drucker-Prager plastic criteria}

Drucker-Prager plastic criteria is suitable for mechanical behavior of granular material like asphalt concrete and is characterized by cohesion and internal friction as in Eq. (4)

$$
f(\overline{\bar{\Sigma}})=\sqrt{\frac{1}{2} \overline{\bar{S}}: \overline{\bar{S}}}+\eta^{*} \cdot p-\xi * . c *
$$

where $c^{*}$ is cohesion, $\eta^{*}$ and $\xi^{*}$ represent internal friction $\varphi^{*}$ of material. In some cases, Drucker-Prager model is equivalent to Morh-Coulomb model as discussed in Refs. [15 - 16].

\section{Plastic flow rule}

Plastic flow rate obeys the following flow rule

$$
\overline{\overline{\dot{E}}}^{v p}=\dot{\gamma} \frac{\partial g}{\partial \overline{\bar{\Sigma}}}
$$

In Eq. (5), $g$ function is potential plastic flow function and has the same form of $f$ function

$$
g(\overline{\bar{\Sigma}})=\sqrt{\frac{1}{2} \overline{\bar{S}}: \overline{\bar{S}}}+\underline{\eta} \cdot p+\text { const }
$$

where $\underline{\eta}$ characterizes dilatant angle of material. The plastic flow rate in Perzyna's model is defined by Eq. (7)

$$
\dot{\gamma}=\zeta \cdot\langle\Phi[f(\Sigma)]\rangle
$$

where $\zeta$ is fluidity of material and function $\Phi[f(\Sigma)]$ represents plastic flow rate. For asphalt concrete, function $\Phi[f(\Sigma)]$ has the form of a power function

$$
\Phi(f(\Sigma))=\left(\frac{f(\Sigma)}{\xi * c^{*}}-1\right)^{\omega}
$$

where $\omega$ is model parameter and Macaulay bracket $\langle\bullet\rangle$ is defined as $\langle\bullet\rangle=\frac{\bullet+|\bullet|}{2}$. 


\section{Hardening law}

Under repeated loading, aggregates are rearranged; therefore the resistance to deformation of asphalt concrete increases with time. As a result, cumulative plastic strain rate decreases with the number of load passes. Park proposed in Ref. [8] that cohesion has its value decreasing with cumulative equivalent plastic strain, whereas Nedjar et al. proposed that viscosity increases with the number of load passes [10]. Inspired of idea in Ref. [10], fluidity $\zeta$ is assumed to decrease with cumulative equivalent plastic strain $e^{v p}$

$$
\zeta=\zeta_{0} \cdot e^{\left(\alpha e^{v p}\right)^{m}}+\frac{\zeta_{1}}{1+\beta \cdot e^{v p}}
$$

where $e^{v p}$ is defined as $e^{v p}=\int_{0}^{t} \overline{\bar{E}}^{v p}: \overline{\bar{E}}^{v p} d t$ and $\zeta_{0}, \zeta_{1}, \alpha, \beta, m$ are model parameters.

\section{NUMERICAL RESOLUTION}

Equations of Perzyna's elasto-viscoplastic model cannot be solved analytically and therefore need to be solved numerically. Return mapping algorithm is widely used for this kind of problem. Interested readers are referred to Refs. [16-17] for more detailed discussion. The numerical resolution of Eqs. [2-9] by means of return mapping algorithm is as follow.

Applying Euler's first order difference for discretising time derivative quantities, one has

$$
\Delta(\bullet)=\frac{d(\bullet)}{d t} \Delta t=(\bullet)_{n}-(\bullet)_{n-1}
$$

where $n$ is current time step and $n-1$ is previous time step, $\Delta(\bullet)$ is difference of $(\bullet)$ between two time steps. For the sake of brevity, any quantity computed at current step will not be indexed by $n$, whereas any quantity related to the previous step will be distinguished by subscript $n-1$.

\section{Elastic prediction}

$$
\begin{gathered}
\overline{\bar{E}}_{\text {trial }}^{e}=\overline{\bar{E}}-\overline{\bar{E}}_{n-1}^{v p} \\
\overline{\bar{\Sigma}}_{\text {trial }}=2 \mu \overline{\bar{E}}_{\text {trial }}^{e}+\lambda t r \overline{\bar{E}}_{\text {trial }}^{e} . \overline{\bar{I}} \\
f_{\text {trial }}\left(\overline{\bar{\Sigma}}_{\text {trial }}\right)=\sqrt{\frac{1}{2} \overline{\bar{S}}_{\text {trial }}: \overline{\bar{S}}_{\text {trial }}}+\eta \cdot p_{\text {trial }}-\xi . c^{*}
\end{gathered}
$$

- If $f_{\text {trial }}\left(\overline{\bar{\Sigma}}_{\text {trial }}\right)<0$, material is still on elastic domain, one has

$$
\overline{\bar{\Sigma}}=\overline{\bar{\Sigma}}_{t r i a l} ; \quad \overline{\bar{E}}^{v p}=\overline{\bar{E}}_{n-1}^{v p}
$$

- Otherwise, material is on viscoplastic domain. One obtains from Eq. (11)

$$
p_{\text {trial }}=\frac{1}{3} \operatorname{tr} \overline{\bar{\Sigma}}_{\text {trial }}=\kappa\left(\operatorname{tr} \overline{\bar{E}}-\operatorname{tr} \overline{\bar{E}}_{n-1}^{v p}\right) ; \quad \overline{\bar{S}}_{\text {trial }}=2 \mu\left(\overline{\bar{E}}^{D}-\overline{\bar{E}}_{n-1}^{v p}\right)+\frac{2 \mu}{3} \operatorname{tr} \overline{\bar{E}}_{n-1}^{v p} \overline{\bar{I}}
$$


where $\overline{\bar{E}}^{D}=\overline{\bar{E}}-\frac{1}{3} \operatorname{tr}(\overline{\bar{E}})$ and $\operatorname{tr}(\overline{\bar{A}})=(\overline{\bar{A}})_{i i}$ is trace of tensor.

\section{Viscoplastic correction}

$$
\overline{\bar{\Sigma}}=\overline{\bar{\Sigma}}_{\text {trial }}-2 \mu \Delta \gamma\left(\sqrt{\frac{1}{2}} \frac{\overline{\bar{S}}}{\|\overline{\bar{S}}\|}+\frac{\eta}{3} \overline{\bar{I}}\right)-\lambda \Delta \gamma \underline{\underline{\eta}} \overline{\bar{I}}
$$

One can derive from Eq. (15)

$$
\overline{\bar{S}}=\overline{\bar{S}}_{\text {trial }}-\sqrt{2} \mu \Delta \gamma \frac{\overline{\bar{S}}}{\|\overline{\bar{S}}\|} ; \quad p=p_{\text {trial }}-\left(\frac{2}{3} \mu \underline{\eta} \underline{\Delta} \gamma+\lambda . \underline{\eta} . \Delta \gamma\right)=p_{\text {trial }}-\kappa \underline{\eta} . \Delta \gamma
$$

where $\kappa=\frac{2}{3} \mu+\lambda$ is bulk modulus. Substituting Eq. (16) in Eqs. (4) and (7), one has a nonlinear equation for determining $\Delta \gamma$

$$
\Delta \gamma=\Delta t . \zeta\left(e_{n-1}^{v p}\right)\left[\frac{\|\bar{S}\|+\eta^{*} \cdot p}{\xi^{*} \cdot c^{*}}-1\right]^{\omega}
$$

\section{DETERMINATION OF MODEL PARAMETERS}

Model parameters in Eqs. (8 - 9) characterize the behavior of asphalt concrete material and can be determined by means of laboratory tests such as triaxial dynamic creep test. Due to the lack of dynamic creep test device, the author makes use of Hamburg Wheel Tracking Test [18 19] results for back calculation of model parameters. The process of determination of model parameters is as follow. Hot mix asphalt was sampled and compacted into a rectangular slab with dimensions $320 \mathrm{~mm} \times 260 \mathrm{~mm} \times 60 \mathrm{~mm}$ by Roller Sector Compactor. After the asphalt concrete slab had been cured for one day, it was maintained in temperature chamber at $60{ }^{\circ} \mathrm{C}$ in air condition. Once the temperature reached stable value, the slab was applied by a rolling rubber wheel of $200 \mathrm{~mm}$ diameter and of $51 \mathrm{~mm}$ width. The rut depth of the slab surface was measured and recorded automatically during the test. When test had finished, one obtained data representing rut depth in relationship with number of load passes (crossings). The mechanics problems simulating the Hamburg Wheel Tracking test are solved with different ranges of input model parameters. The input parameters producing rut depth curve which fits well tested one are model parameters to be determined. Other materials like graded aggregates and foundation can be treated as elastic material of which elastic modulus and Poisson ratio can be determined by testing at laboratory or refering to current design guide [20].

\section{CALCULATION RESULTS}

This section presents the calculation results which are carried out on the basis of the previous formulation and compared with monitoring data for validation purpose. All numerical results have been obtained by a homemade finite element program developed under Intel Visual Fortran environment. 


\subsection{Modelling of Hamburg Wheel Tracking Test}

In this test, the wheel travels along the length of the slab in a straight line; therefore, one can consider that the slab is in plane strain conditions [6 - 7]. Due to symmetry, just a half of the problem is considered as shown in Fig. 1. The slab is made of dense graded modified asphalt concrete and is $320 \mathrm{~mm}$ long, $260 \mathrm{~mm}$ wide, $60 \mathrm{~mm}$ thick. The total vertical load applied by the rubber wheel to the sample is $710 \mathrm{~N}$. The contact area spreads over an area of $51 \mathrm{~mm} \times 20 \mathrm{~mm}$ and the average contact pressure is $0,7 \mathrm{MPa}$. Boundary conditions of the problem are as follow. Horizontal displacements are restrained for all nodes at the left side of the slab and those on the symmetric line. All nodes at the bottom of the slab are fixed for all displacements.

Elastic modulus of asphalt concrete at $60^{\circ} \mathrm{C}$ is $E=200 \mathrm{MPa}$ for $\mathrm{C} 12.5$ and $E=250 \mathrm{MPa}$ for $\mathrm{C} 19$ and $\nu=0,35$. The cohesion, internal friction and dilatant angle are $c^{*}=25 \mathrm{kPa}, \varphi^{*}=28^{\circ}$ and $\psi^{*}=5^{\circ}$, respectively. One should be noted that $\left(c^{*}, \varphi^{*}\right)$ are different from classical $(c, \varphi)$. Classical $c$ and $\varphi$ characterize limit state at which structure is not yet unstable and are determined based on static tests like simple shear test and triaxial shear test, whereas $c^{*}$ and $\varphi^{*}$ characterize limit state at which behavior of structure is still elastic and must be determined based on dynamic tests like triaxial dynamic creep test. In this work, values of $c^{*}$ and $\varphi^{*}$ are back calculated from Hamburg Wheel Tracking test results.

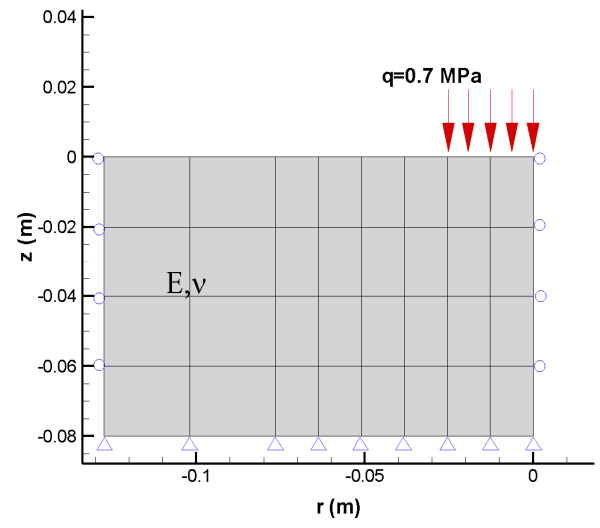

Figure 1. Mechanics problem simulating Hamburg Wheel Tracking test.

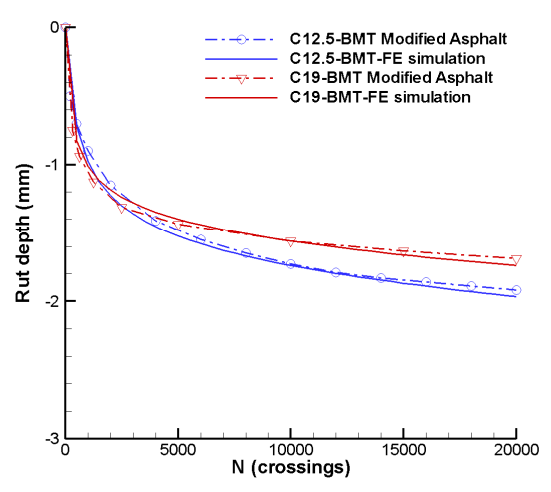

Figure 2. Rut depth in function of number of crossings.

Loading time is the time the wheel takes to travels a distance of tire print length [6]. For a velocity of $1.1 \mathrm{~km} / \mathrm{h}$, loading time of a load pass is $T_{L}=0.065 \mathrm{~s}$. The rut depth curves calculated and tested of two materials (C12.5 and C19 produced with BMT modified asphalt) are shown in Fig. 2. The model parameters of these materials are determined and represented in Tab. 1. 
Table 1. Model parameters of dense graded asphalt concretes.

\begin{tabular}{ccccccc}
\hline \multirow{2}{*}{ Material } & \multicolumn{7}{c}{ Model parameters } \\
\cline { 2 - 7 } & $\xi_{0}$ & $\xi_{1}$ & $\alpha$ & $\beta$ & $m$ & $\omega$ \\
\hline $\mathrm{C} 12,5$ & $2,5 \times 10^{-3}$ & $1,75 \times 10^{-5}$ & 39 & 39 & 1,5 & 1,0 \\
$\mathrm{C} 19$ & $3,0 \times 10^{-3}$ & $1,50 \times 10^{-5}$ & 45 & 45 & 1,5 & 1,0 \\
\hline
\end{tabular}

\subsection{Application for predicting pavement permanent deformation}

In this section, model parameters determined above are used to predict the pavement permanent deformation of two specific projects in the South of Vietnam.

\subsubsection{Experimental project on National Road $1 \mathrm{~A}$}

An experimental project for BMT modified bitumen was performed at National Road 1A adjoined to "Hot mix asphalt recycling at plant" experimental project. The pavement structure of this project (Fig. 3) consists of two hot mix asphalt layers and a graded aggregate layer as described below

- dense graded asphalt concrete layer C12.5 of thickness $5 \mathrm{~cm}$ produced with BMT modified bitumen;

- dense graded asphalt concrete C19 of thickness 7cm produced with BMT modified bitumen;

- graded aggregates layer of thickness $50 \mathrm{~cm}$; of elastic modulus $E=250 \mathrm{Mpa}$; of Poisson ratio $v=0,3$;

- foundation of elastic modulus 50MPa, of Poisson ratio $v=0,3$.

Applied load is 13-ton dual tire axle. Current technology tires are much more inflated than they were in the past. Tire pressure varies commonly from 0.8 to $1.0 \mathrm{MPa}$ [21]; therefore, an average contact pressure of $0.9 \mathrm{MPa}$ is chosen for calculation in this work. Due to symmetry, just a half of problem is considered. Figure 4 represents the dual tire print of a half of an axle. The length of print is $167 \mathrm{~mm}$. Average vehicle velocity of $10 \mathrm{~km} / \mathrm{h}$ is chosen for near intersection area and corresponding loading time is 0.06s. Standard calculating temperature is $60{ }^{\circ} \mathrm{C}$.

The program takes about 18 hours to complete the calculation. After one million of load passes, the total rut depth (including upheaval) predicted is $17.84 \mathrm{~mm}$. Cross section at tire print position varied with number of load passes is shown in Fig. 5.

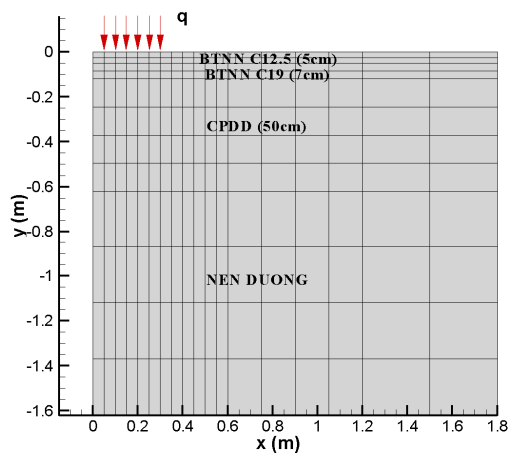

Figure 3. Pavement structure.

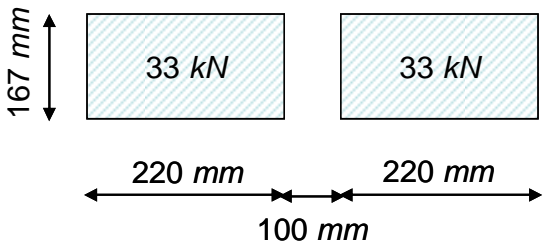

Figure 4. Dual tire print dimension. 
The pavement was monitored its deformation by surveying method after 1 month, 3 months and 6 months of exploitation. After 6 months, section laid with recycle hot mix asphalt deformed too much. The entire experimental project including several different sections was milled out for repaving; therefore monitoring data ended up after 6 months.

In order to compare the predicted rut depth with the measured one, traffic volume circulating on the tested section was taken from the nearest tollgate and converted into number of Equivalent Single Axle Load (ESAL) by the method described in appendix A of design code 22TCN 211-06 [20, p. 59]. In reality, pavement temperature is not a constant value but varies with time. Traffic volume at other temperature can be converted into standard temperature $\left(60{ }^{\circ} \mathrm{C}\right)$ by mean of temperature factor as proposed in [22]. At the time of monitoring, there were three lanes in one direction of travel. The outermost lane reserved to cars and light trucks, the inner one reserved to heavy trucks and the last one for motors and bicycles. Based on statistics, the number of ESALs travelling on the heavy truck lane (monitoring lane) was 140.000 ESALs/lane/month.

Total rut depth curves predicted and measured are shown in Fig. 6. Total rut depth measured is $20.0 \mathrm{~mm}$ after 840.000 ESALs (or 06 months of exploitation) and the predicted value is $16.74 \mathrm{~mm}$. The difference between the predicted and measured values is $16.3 \%$.

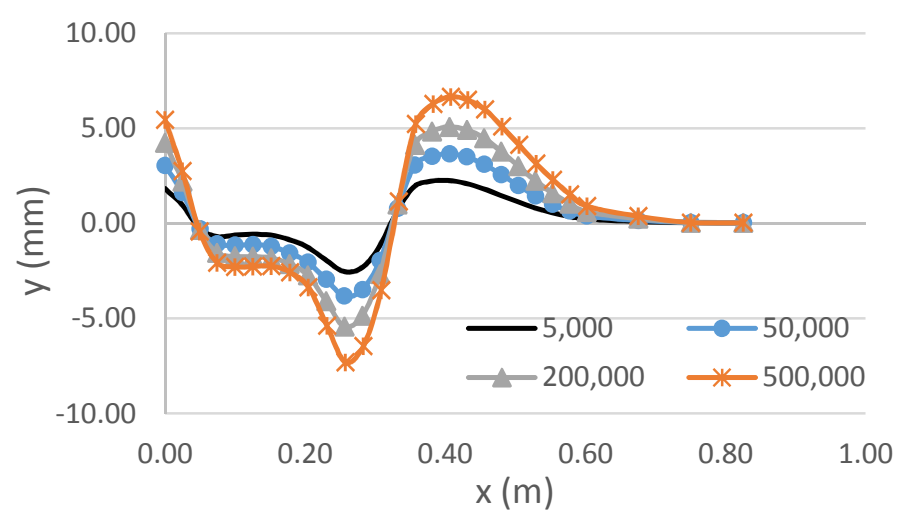

Figure 5. Cross section at tire print position. Vertical scale is amplified 1000 times.

\subsubsection{East-West Highway Reparation Project}

The pavement of East-West Highway - Ho Chi Minh City has exhibited severe rutting distress due to very high traffic volume moving in and out of Cat Lai port. The pavement was repaired with both asphalt and cement concrete materials on October 2014. For the sections repaired with asphalt concrete, the pavement structure consists of several layers as described below

- dense graded asphalt concrete layer $\mathrm{C} 19$ of thickness $5 \mathrm{~cm}$ produced with polymer modified bitumen of grade three (PMB3);

- dense graded asphalt concrete layer C19 of thickness $7 \mathrm{~cm}$ produced with PMB3;

- pavement base of equivalent elastic modulus $E=160 \mathrm{Mpa}$;

Model parameters of dense graded asphalt concrete C19 produced with PMB3 are $\xi_{0}=5,0 \times 10^{-3}, \xi_{1}=5,0 \times 10^{-6}, \alpha=\beta=46,5, m=1,55$ and $\omega=1,0$. 
The predicted zone is at the intersection of East-West Highway and Dong Van Cong Street; therefore, traffic velocity has lower value than that in the previous example, namely $5 \mathrm{~km} / \mathrm{h}$. Other calculating conditions are the same as those in the previous example. Traffic volume is taken from Xa Lo Ha Noi tollgate data and converted into number of Equivalent Single Axle Load (ESAL) by means of the method described in appendix A of design code 22TCN 211-06 [20, p. 59].

There are two separate heavy truck lanes in one direction of travel on East-West Highway. Based on statistics, the number of ESALs travelling on two heavy truck lanes (monitoring lanes) is 274.000 ESALs/month, i.e. 137.000ESALs/lane/month. The pavement was monitored its deformation after 1.5 months, 2.5 months and 3.5 months by straight edge as described in standard ASTM E1703 with a density of one section/30 m. Total rut depth curves predicted and measured are shown in Fig. 7 in which total rut depth measured is $8.2 \mathrm{~mm}$ after 479.500 ESALs (or 3.5 months of exploitation) and the predicted value is $9.4 \mathrm{~mm}$. The differences between the predicted and measured values is less than $14.6 \%$.

\subsubsection{Conclusion}

As can be seen from the examples above, rut depth values predicted by proposed method fit relatively well those measured on the field. The differences between the predicted and observed values are less than $16.3 \%$. Because of many random factors such as pavement temperature, distribution of traffic flow over time as well as errors in terms of geometry and material, this level of accuracy can be accepted.

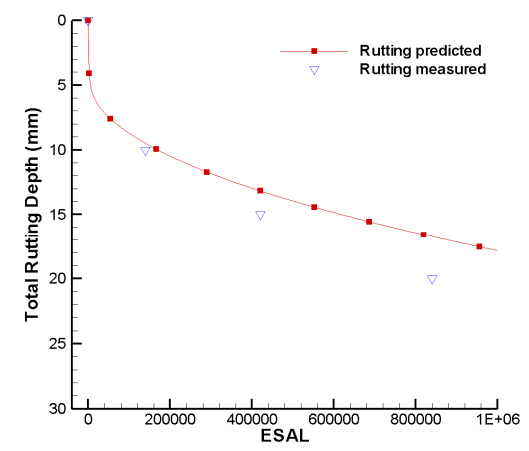

Figure 6. Total rut depth predicted and measured. Experimental project on National Road 1A. The project was performed as extension of "Hot mix asphalt recycling at plant" project - A project of Institute of Transport Science and Technology and BMT Investment Construction Joint Stock Company.

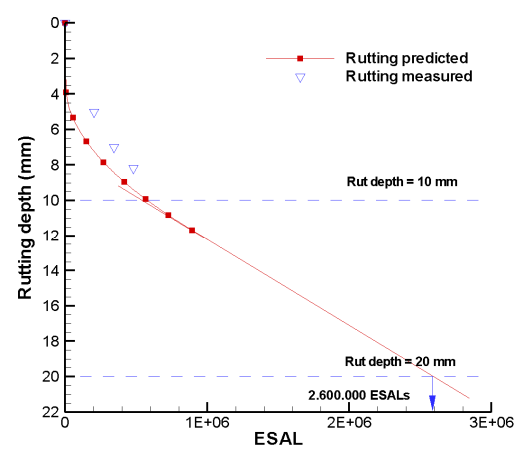

Figure 7. Total rut depth predicted and measured. East-West Highway Reparation Project.

\section{CONCLUSIONS}

Perzyna's elasto-viscoplastic model using Drucker-Prager criteria was modified for calculating flexible pavement permanent deformation in large deformation conditions. The main key of the method proposed is that Hamburg Wheel Tracking test results are used for determining material constants and predicting rut depth of pavement. Most of factors causing rutting are explicitly taken into account in the calculation, namely ESAL, tire inflatable pressure 
and traffic velocity, whereas the influence of temperature factor on the calculation results is hidden on model parameters determined from laboratory test results.

The formulation proposed is illustrated and validated by means of specific examples of calculation. The first example is dedicated to back calculating model parameters while the last two examples simulate behavior of real pavement structure. The prediction of pavement permanent deformation with proposed method reaches acceptable level of accuracy.

The program does not takes long time to finish calculation, approximately 12-24 hours for a pavement problem. Therefore, one can predict quickly the behavior of a pavement after millions of load passes and the allowable number of ESALs. This contributes to the assessing of material usability depending on different exploitation condition of every project.

\section{REFERENCES}

1. American Association of State Highway and Transportation Officials - MechanisticEmpirical Pavement Design Guide-A Manual of Practice, Washington, 2008, pp.36-38.

2. Indian Road Congress - IRC: 37-2012: Guidelines for the Design of Flexible Pavements, New Delhi, 2012, pp. 15.

3. Kenis W.J. - Report No FHWA-RD-77-154: Predictive Design Procedures-VESYS Users Manual, Federal Highway Administration, Washington, 1978, pp.24-26.

4. Huang Y.H. - Pavement Analysis and Design (second edition), Person Prentice Hall, New Jersey, 2004, pp. 318-320.

5. Kim J.R., Drescher A. and Newcomb D. - Technical Report: Rational Test Methods for Predicting Permanent Deformation in Asphalt Concrete Pavement, Minnesota Department of Transportation, Minnesota, 1991, pp. 22-28.

6. Hua J. - Ph.D. Thesis: Finite element modelling and analysis of accelerated pavement testing devices and rutting phenomenon, Purdue University, West Lafayette, 2000, pp. 75100.

7. Nahi M.H., Ismail A. and Ariffin A.K. - Analysis of Asphalt Pavement under Nonuniform Tire-pavement Contact Stress using Finite Element Method, Journal of Applied Sciences 11 (2011) 2562-2569.

8. Park D.W. - Simulation of Rutting Profiles Using a Viscoplastic Model, KSCE Journal of Civil Engineering 11 (2007) 151-156.

9. Karrech A., Seibi A. and Duhamel D. - Finite element modelling of rate-dependent ratcheting in granular materials, Computers and Geotechnics 38 (2011) 105-112.

10. Nedjar B. and Nguyen D.T. - On a simple cyclic plasticity modeling with implicit kinematic hardening restoration, Annals of Solid and Structural Mechanics 4 (2012) 3342.

11. Lu Y. and Wright P.J. - Numerical approach of visco-elastoplastic analysis for asphalt mixtures, Computers and Structures 69 (1998) 139-147.

12. Huang C.W. et al. - Three-Dimensional Simulations of Asphalt Pavement Permanent Deformation Using a Nonlinear Viscoelastic and Viscoplastic Model, Journal of Materials in Civil Engineering 23 (2011) 56-68. 
13. Darabi M.K. et al. - A modified viscoplastic model to predict the permanent deformation of asphaltic materials under cyclic-compression loading at high temperatures, International Journal of Plasticity 35 (2012) 100-134.

14. Perzyna P. - Fundamental problems in viscoplasticity. In: Chernyi G.G. (Ed.) Advanced Applied Mechanics, Academic Press, New York, 1966, pp. 243-377.

15. Chen W.F. and Mizuno E. - Nonlinear Analysis in Soil Mechanics: Theory and Implementation, Elsevier, Amsterdam, 1990, pp.143-150.

16. Souza Neto E.A., Peric D. and Owen D.J.R. - Computational Methods for Plasticity: Theory and Applications, Wiley, Singapore, 2008, pp.466-467.

17. Simo J.C. and Hughes T.J.R. - Computational Inelasticity, Springer, New York, 2000, pp.35-38.

18. European Standard - EN12697-22: Bituminous mixtures. Test method for hot mix asphalts-Part 22: Wheel Tracking, Brussels, 2007, pp. 1-28.

19. Ministry of Transport - QĐ1617: Technical Stipulation of Test for determining rut depth of asphalt concrete by Wheel Tracking Device, Hanoi, 2014, pp. 1-26.

20. Ministry of Transport - 22TCN 211-06: Flexible pavement-Requirements and Design Guide, Hanoi, 2006, p. 36.

21. Kawa I., Zhang Z. and Hudson W.R. - Technical Report: Evaluation of the AASHTO 18kip Load Equivalency Concept, Center for Transportation Research - Bureau of Engineering Research, The University of Texas at Austin, Austin, 1998, pp. 9.

22. Park D.W. - Traffic Loadings Considering Temperature for Pavement Rutting Life, KSCE Journal of Civil Engineering 10 (2006) 259-263.

\title{
TÓM TẮT
}

\section{TÍNH TOÁN BIẾN DẠNG VĨNH CƯUU CỦA KÊT CÂUU ÁO ĐƯỜNG SỬ DỤNG MÔ HİNH ĐÀN HỒI-DẺO-NHỚT PERZYNA}

\author{
Nguyễn Huỳnh Tấn Tài ${ }^{1,2, *}$ \\ ${ }^{1}$ Khoa Xây Dựng, Truờng Đại học Thủ Dầu Một \\ ${ }^{2}$ Phòng Nghiên cứu Phát triển và Thí nghiệm, Công ty CP Đầu tu Xây dựng BMT \\ *Email: tainht@tdmu.edu.vn,tainht@bmt-rnd.vn
}

Bài viết này trình bày một phương pháp tính toán biến dạng vĩnh cửu của kết cấu áo đường mềm dưới tác dụng trùng phục của tải trọng xe cộ. Ứng xử cơ học của lớp mặt đường mềm được mô tả bằng quy luật đàn hồi-dẻo-nhớt của Perzyna. Biến dạng vĩnh cửu của kết cấu áo đường được tính toán tuần tự sử dụng phương pháp phần tữ hữu hạn phi tuyến. Các thông số của mô hình được xác định dựa vào thí nghiệm độ sâu vệt hằn bánh xe Hamburg Wheel Tracking.

Tù khóa: biến dạng vĩnh cửu, dự tính độ sâu vệt hằn bánh xe, mô hình đàn hồi-dẻo-nhớt, biến dạng lớn. 